ISSN: 2162-3104 Print/ ISSN: 2166-3750 Online Volume 6, Issue 3 (2016), pp. 762-778 (C) Journal of International Students http://jistudents.org/

\title{
Unfulfilled Expectations: Influence of Chinese International Students' Roommate Relationships on Sense of Belonging
}

\author{
Christina W. Yao \\ University of Nebraska-Lincoln, USA
}

\section{ABSTRACT}

Findings from this study indicate that more attention must be given to Chinese students' interpersonal relationships with domestic students, particularly when considering the role of daily cross-cultural interactions in residential living. Participants who wanted American roommates anticipated an easier transition to U.S. culture. However, making meaningful connections with American students proved to be more challenging than anticipated. Participants reported that cultural differences within their residence hall room led to difficulty with communication and social connections.

Keywords: Chinese Students, International Students, Roommate Relationships, Sense of Belonging, Residence Life

Chinese international students are the largest international population on college campuses in the United States (Institute of International Education, 2013; UNESCO Institute for Statistics, 2014; Yan \& Berliner, 2010). Student mobility from China consisted of over half a million students in 2012, with the United States as their top destination (UNESCO Institute for Statistics, 2014). The United States accepted over 19\% of the mobile students from China, with 178,890 Chinese nationals enrolling in U.S. institutions (UNESCO Institute for Statistics, 2014).

Despite the prevalence of Chinese students on campuses, many Chinese students report feelings of marginalization (Lee, 2010; Sherry, Thomas, \& Chui, 2010). Feelings of isolation reported by international students often lead to negative implications for academic and co-curricular success (Lee \& Rice, 2007; Smith \& Khawaja, 2011). Many international students experience transition issues; however, several studies indicate that 
there are differences in experiences within international student sub-groups (Lee, 2010; Lee \& Rice, 2007; Li \& Kaye, 1998; Wilton \& Constantine, 2003), specifically between European nationals and Asian students. Students from Asia often have more difficulty than Western European international students in many areas affecting their transition to university in the United States, most notably with issues of isolation, language, and social integration.

Residence halls are often considered the epicenter of student engagement (Astin, 1993; Pascarella \& Terenzini, 2005) since residential students spend most of their on campus time in residential facilities (Shushok, Scales, Sriram, \& Kidd, 2011). Campus residences halls are considered to be positively influential environments for students to both live and learn. Community building and intercultural interactions are often at the heart of residential programs since the close proximity and structured learning opportunities promote student engagement and learning (Blimling, 2010; Pascarella \& Terenzini, 2005; Pascarella, Terenzini, \& Blimling, 1994; Pike, 2002). Residence halls are settings in which diverse students, including international scholars, are able to thrive and flourish both academically and socially, with the intention of contributing to students' overall sense of belonging to their communities. However, very few studies examine the interpersonal experiences of Chinese international students in residence halls in the United States and the effect on their sense of belonging.

Peers and other campus community members affect students' sense of belonging, which is defined as students' feelings of identification and affiliation with the university community (Hausmann, Ye, Schofield, \& Woods, 2009; Strayhorn, 2012). Peer relationships are important factors in the collegiate experiences of undergraduate Chinese international students. Daily social interactions serve as a basis for Chinese international students' feelings of either belonging or exclusion on the college campus. It is imperative to examine the experiences of undergraduate Chinese international students to better understand the challenges in the residence halls, leading to implications for the success and persistence of undergraduate Chinese international students at in the United States.

Many institutions require that all first-year students live in university housing; however, little research exists on international students' perceptions of the climate in residence halls and virtually no research specifically on Chinese international students' experiences in residence halls. In this current study, the experiences affecting the sense of belonging in first-year undergraduate Chinese international students who are required to live in residence halls are illuminated, and insights are provided on these students' perception of their peer interactions within their new residential home on campus. The research questions guiding this study are: 
- What were Chinese international students' expectations of roommate relationships on U.S. campuses?

- What is the influence of roommate relationships on first-year

Chinese international students' sense of belonging in the residence halls?

\section{LITERATURE REVIEW}

Studies on sense of belonging typically focus on domestic student populations as the study participants. The experiences of underrepresented student populations are at the forefront of sense of belonging research (e.g., Berger, 1997; Hausmann et al., 2007; Hurtado \& Carter, 1997; Johnson et al, 2007; Museus \& Maramba, 2011), with virtually no attention to international students as a campus sub-group. With this in mind, the review of literature provides an examination of sense of belonging research on domestic students and then extends this research to international students.

\section{Sense of Belonging in College Students}

Sense of belonging is based on students' perceptions of institutional support and interpersonal relationships, with potential to positively influence students' persistence and academic success (Hausmann et al., 2009). Sense of belonging is particularly important for students from underrepresented populations (Strayhorn, 2012) since feelings of belonging elicit a sense of connectedness with, affiliation for, and acceptance by the larger campus community. Additionally, students' sense of belonging at the university as a whole is often strongly associated with their sense of social acceptance, implying that sense of belonging is primarily influenced by social interactions and perception of acceptance by students' peers (Freeman, Anderman, \& Jensen, 2007).

In current literature, differences were found in feelings of belonging from historically underrepresented students and White students. For example, Berger (1997) found that living on campus had a positive relationship to students' socialization and sense of community. However, White students were more likely to identify with the community in their residence halls than were students of color. This finding may indicate that there is "a dominant peer normative environment" (Berger, 1997, p. 449) that affects underrepresented students' sense of belonging.

Racial differences in students' sense of belonging were also found in another study conducted with students living in residential communities. Johnson et al (2007) examined the sense of belonging in first-year students from different racial/ethnic groups and found that students of color perceived a lower sense of belonging on their campuses than White students. The residence hall can be a "compelling environment for shaping 
students' sense of belonging” (Johnson et al., 2007, p. 536), which is similar to previous studies that found positive effects of residence halls (Berger, 1997). Although studies in residence halls may have positive implications for international students, most of these studies only include domestic students and do not examine how cultural differences and language barriers may affect international students' sense of belonging in a residence hall.

\section{International Student Adaptation}

Parallel to the concept of sense of belonging, social adaptation is a common theme in international students' experiences at colleges in the United States. Sherry, Thomas, and Chui (2009) conducted a study in which participants, who came from 30 different countries, reported issues with language, adapting to new cultural norms, and developing friendships. Several participants in the study, primarily those from Asia and the Middle East, reported feelings of isolation and a lack of connection with university community members. The findings from this study, as well as others (Pan \& Wong, 2011; Yan \& Berliner, 2011), indicate that Asian cultural backgrounds can add more significant barriers in adapting to a new campus environment, particularly since the high acculturation distress can bring increased psychological distress (Wilton \& Constantine, 2003).

According to Yan and Berliner (2011), early support is needed for newly arrived Chinese international students in a foreign environment. Newly arrived students tended to have higher levels of anxiety related to language, academic challenges, and cultural differences. Although most participants in the study indicated that they were interested in acculturating to their new environment through integration strategies, most participants tended to be more separated from the domestic students by withdrawing from social activities and socializing only with others in the Chinese community.

As a whole, international students are more likely than domestic students to feel isolated from the rest of campus because of cultural differences, which have both academic and social implications (Lee \& Rice, 2007; Smith \& Khawaja, 2011). Understanding the experiences of undergraduate Chinese international students in their residential environment is imperative to supporting these students through the academic and social aspects of their collegiate career. If these students do not feel a sense of belonging, they are at risk for being unsuccessful in college and may not persist to graduation (Tinto, 1993). In addition, the early years of college is critical since that time ensures students' sense of belonging and persistence, and the institutional environment and culture are correlated to students' collegiate success (Astin, 1994; Pascarella \& Terenzini, 2005; Tinto, 1993), particularly for Chinese students. These students' perceptions of their surrounding environment are an important factor in developing a 
sense of belonging which leads to students reporting a more positive perception of their campus climate (Glass, 2012). However, these studies are not situated in the campus residential setting, indicating a need further examine the influence of roommate relationships on Chinese students' sense of belonging.

\section{CONCEPTUAL FRAMEWORK}

Sense of belonging, which includes feelings of membership and affiliation with a particular group, is used as an overarching concept to examine Chinese students' experiences. Sense of belonging is applied to this study since it provides a framework for understanding Chinese international students' perception of membership into their residential community. The comprehensive definition for this study came from Strayhorn's (2012) hypothesized model of college students' sense of belonging, which includes:

Sense of belonging refers to students' perceived social support on campus, a feeling or sensation of connectedness, the experience of mattering or feeling cared about, accepted, respected, valued by, and important to the group (e.g., campus community) or others on campus (e.g., faculty, peers). (p. 3)

In applying Strayhorn's (2012) model, international students enter social spaces and contexts (e.g., residence halls) in which their basic needs (e.g., sense of belonging) emerge to drive their behaviors. Positive outcomes from achieving sense of belonging include persistence and happiness (Strayhorn, 2012); conversely, negative outcomes could include unhappiness and feelings of isolation.

\section{RESEARCH METHOD}

A phenomenological orientation is used in this study in order to illuminate and understand the lived experiences (Van Manen, 1990) of the participants through an interpretive lens that situated their experiences within a specific context (Merriam, 2009). The phenomenon of sense of belonging is examined, with participants describing their overall experiences in their residential communities. In doing so, the commonalities among participants were reduced from "individual experiences with a phenomenon to a description of the universal essence" (Creswell, 2007, p. 58). The "essence" of the phenomenon was revealed through a "systematic attempt to uncover and describe the structures, the internal meaning structures, of lived experience” (Van Manen, 1990, p. 10). 
Midwest University (MWU), a pseudonym given to the actual institution, was chosen as the study site since it has a large residential population as well a large international student population. MWU was a large, public land-grant research institution in the Midwest with over 33,000 undergraduate students enrolled in Fall 2012. MWU had approximately one in eight first-year MWU students identify China as their country of origin in Fall 2012. All first-year, non-commuter students were required to live on campus. Anecdotally, MWU is considered to be an institution of higher education that is doing well in acculturating the many international students on its campus.

Participants were recruited through emails sent to eligible participants from MWU's Office of the Registrar. Emails were sent to all eligible participants who identified as undergraduate Chinese international students in their first year at the university who lived in the residence halls. All 21 participants were first-year students from China who were completing their second semester at Midwest University. The participants included six men and 15 women. Each participant chose a pseudonym, which are used throughout this study. All interviews were conducted in English. For clarification, participants used the term "American" to refer to U.S.-born students; therefore, "American" is used interchangeably with "domestic students" throughout this study.

All first interviews were conducted prior to the end of the 2013 spring semester. Second round interviews were conducted at the start of the 2013 fall semester with 17 of the 21 participants. In-depth interviews were conducted with each participant in a person-to-person format and the audio was digitally recorded. The semi-structured interviews included broad questions related to participants' sense of belonging in the residence halls. Examples of questions include: "describe your relationship with nonChinese students in your residence hall" and "how much does feeling like a member of that community matter to you?”

Transcriptions were completed immediately following each interview, which allowed for analyzing the data and organizing all hand written notes. The second round interview assisted in obtaining deeper and richer information from the participants.

\section{Coding and Analysis}

Researcher reflexivity in research is essential due to the relational nature between researcher and participants (Glesne, 2006; Patton, 2002). The essences of participants' experiences were interpreted through my lens as a U.S.-born Chinese-American. To address what I bring as a researcher, the first part of analysis was to complete thorough reviews of interview transcripts while reflecting down my reactions and responses to participants' experiences. Transcripts were first manually coded on paper copies by 
writing codes in the margins and highlighting relevant text. Then transcripts were uploaded electronically in Dedoose and then reviewed again with electronically applied codes. Results between the paper copies and electronic versions were compared to check for consistency.

Categories were made based on the research questions and conceptual framework, which was consistent with analysis typically conducted in phenomenology (Rossman \& Rallis, 2003). In the first cycle of coding, initial codes for large data chunks were created, utilizing deductive coding, which includes a "start list” (Miles et al., 2014, p. 81) based on this study's interview protocol and conceptual framework. Themes were developed from emergent broad categories based on the participants' experiences. Themes were coded by "lifting appropriate phrases or by capturing in singular statements the main thrust of the meaning of the themes" (Van Manen, 1990, p. 93). Descriptive coding was used to "provide an inventory of topics for indexing and categorizing” (Miles, Huberman, \& Saldana, 2014, p. 74). Emotion coding was used in addition since it is appropriate for "studies that explore intrapersonal and interpersonal" experiences (Miles et al., 2014, p. 75).

Second cycle coding was used as "a way of grouping those summaries into a smaller number of categories, themes, or constructs" (Miles et al., 2014, p. 86). First cycle codes were clustered under common themes that emerged from the interviews. An iterative process was used while reflecting and clustering codes into code categories. The pattern codes were continuously refined and restructured until final codes emerged that represented the lived experiences verbalized by the participants. Several themes emerged, including issues related to discrimination, awareness of being an outsider, and perception of language ability. For the purpose of this particular study, the influence of roommate relationships on Chinese students' sense of belonging is examined as the analytical sample from a larger study.

\section{Trustworthiness and Validity}

Triangulation was used to support the validity of this study. Two techniques were used in this study: the use of multiple points in time and member checks (Merriam, 2009). Two interviews with each participant allowed for multiple points in time and created the opportunity to crosscheck and compare data between the two interviews. The use of two interviews also allowed for member checks, which provided feedback on emerging findings and interpretation from the first interviews. In addition to multiple data sources, data was triangulated with peers who, as qualitative researchers, were able to critique findings and provide alternative viewpoints. 


\section{Limitations}

Participants were interviewed at one point in time in their collegiate career, which could pose as a limitation. Although second round interviews were done four months after the first, this does not allow for significant change to occur with participants' experiences. Participants may not have had time to fully reflect and make meaning of their first year. Also, all interviews were conducted in English, which presents some language limitations for the participants. However, questions were often repeated and rephrased in order to assist in participants' understanding.

\section{FINDINGS}

Findings for this study are organized in two sections based on the research questions related to expectations of roommate relationships prior to arriving on campus and the realities of roommate relationships for Chinese international students. More attention is given to the findings related to the realities of roommate relationships since they elicit more significant implications for practice.

\section{Expectations of Roommate Relationships}

The participants viewed having an American roommate as an automatic path to better English skills and to better understanding of American culture. Eighteen of the participants cited two main reasons for their desire to room with a domestic student: the ability to practice speaking English and immerse themselves in American culture. Some participants were disappointed to find out they were rooming with another Chinese student. When asked about her roommate, Rachel explained:

I want an American student because I ... it's kind of selfish, but I think if you have a roommate with really good English [it is good]... I even talked to my RA to try to apply for an American roommate.

Similarly, Camilla's reason for wanting a domestic roommate was based on her desire to speak English on a daily basis. She also hoped to "get involved into American society instead of Chinese society." Many participants felt that an American roommate would connect them to additional American friends. Peter expressed this thought by saying, "I think it's better to get an American roommate. It's better because if I just get an American roommate, I can more easily join the American group. It's faster maybe.”

Many of the study participants viewed American students as the easiest way to feelings of connectedness and belonging on campus. 
American students were viewed as teachers and guides who would be able to help Chinese students acclimate faster to American culture.

Of the 21 participants, three participants requested a Chinese roommate due having similar cultural experiences and a common language. For example, Vicky had met a Chinese student online through social media prior to arriving on campus, and explained her reasons for selecting a Chinese roommate:

I'm afraid I would not get along with Americans because the culture difference and the habits we have, they are different. So I think it would make me feel uncomfortable so I decided to choose Chinese student who was in high school here, in the U.S. Because she is Chinese, we don't have much difference.

Nancy and Gwen also decided that a common language and shared culture would assist them in feeling more comfortable in their residential community. Their rationale for Chinese roommates indicated different priorities from other participants who wanted the opportunity to immerse themselves immediately into American culture through interactions with a domestic roommate. Interestingly, this indicates that all students knew their roommates would be instrumental to their sense of belonging in their residential space; however, the fulfillment of their expectations were varied after all participants arrived on campus and moved into their residence hall.

\section{Realities of Roommate Relationships}

All study participants expected that an American roommate would assist in their transition to MWU and to their residential community. Twelve of the 21 participants were assigned a Chinese roommate. Of that 12, only three requested a Chinese student for a roommate. Of participants who had roommates randomly assigned to them, most stated that they wanted an American roommate. However, only nine of the participants were housed with an American roommate, and several of these participants stated that their feelings towards their American roommates changed over time. The early anticipation and excitement of living with a domestic student soon faded after realizing that the cultural differences caused discomfort in their room.

\section{Challenges with American roommates.}

Kay was excited to be paired up with an American roommate, assuming that close proximity would foster improved communication and cultural exchange. However, partway through the first semester, she and her roommate only communicated when necessary. Kay found that having an 
American roommate led to some dissatisfaction in her room. She eventually moved rooms, explaining:

Last semester, I lived with a White girl. We lived together but we don't really have any mutual topics. So every time, every night, when we sit in one room we just keep silent. That's so bad. Actually, we did know that we can get along well but we just don't have much mutual topics. And this semester, I moved out and I live with one of my Chinese friends. We have more topics to talk about.

Kay's situation with her roommate, which was a fairly neutral relationship with no hostility, appeared to be common among the participants who had American roommates. Zoey, who was originally very excited to live with a non-Chinese student, had a similar experience, stating, "We talk[ed] a lot at the beginning, but I think when time goes by, we don't have so much interest in each others' culture. And so we don't communicate a lot. Just necessary talk.”

Zoey was vocal about her roommate having no interest in Chinese culture, which was surprising to her. Zoey thought her American roommate would have a lot of questions since Chinese and American cultures are so different; however, Zoey realized that "maybe she has no interest in that." After many attempts at conversation, Zoey stopped trying to connect with her roommate.

Camilla's relationship with her American roommate also changed during the academic year. Her early experience was positive when her American roommate would assist Camilla with her transition to the United States. However, their relationship never developed beyond the surface level of cohabitating. Camilla stated:

I can't say it's too good because we're not familiar with each other even though we live in the same room for nearly one year now. But I have some problems in my heart is that I just feel like we're just roommates instead of friends. It can be kind of a language problem between us. And some cultural problem between us.

Camilla attended a Canadian foreign language high school in China for two years before coming to college in the United States. Even with her early introduction to Western culture, Camilla still had a difficult time finding common conversation topics with her roommate due to cultural differences. Although Camilla was deliberate about requesting an American roommate, she decided to move off-campus with Chinese international friends for her second year. 
Derek, a member of a living-learning program, had a difficult time with his roommate. Derek's roommate was very disengaged and that led to Derek having negative experience in his living-learning community. Derek explained:

We don't really have common language and we don't have the same topics we are both interested in. So we don't really have any topics to talk about. So that's why we don't really get along. It's not like we don't get along, we don't talk. We never bother each other, we have different social lives.

Derek spoke about his feelings of loneliness and disconnection from his second roommate and his floormates. He credited his discomfort to the fact that he was the only Chinese international student in his living-learning community. Because of this, he had a very difficult time finding other students who wanted to connect with him, leading to feelings of dissatisfaction with his living environment.

\section{Benefits of Chinese roommates.}

Overall, participants who had Chinese roommates tended to have higher sense of belonging in their rooms although not necessarily in the larger residence hall. As a result, when asked why they are able to cohabitate effectively with their Chinese roommates, participants responded that it was easier to live with someone who shared the same culture and language. These participants expressed a sense of relief to be able to return to their rooms and be comfortable around those that are culturally similar.

Jack had a positive experience with his Chinese roommate, who was from his hometown of Shenzhen. They live in a four-person suite with two American students. Jack described that living situation as being the best possible scenario for an international student. He was able to have a roommate with the same cultural background, but was able to get exposed to American culture in his room with his two domestic roommates. When asked about the benefits of his living situation, Jack stated, "It's more convenient because sometimes we talk about things only Chinese can understand. And if with the two American guys, we can also talk about American culture.”

Nancy requested a Chinese roommate prior to her arrival to Midwest University. She reported a high level of happiness and connection with her roommate, stating that, "I feel like she's more than my roommate. A friend and kind of like a sister." Vicky, who also requested a Chinese roommate, shared that her roommate relationship was very positive. When asked about her Chinese friends' experiences, Vicky said that most of her friends with American roommates were the ones who had roommate 
problems. Although Vicky had originally thought she would make a lot of American friends in her residence hall, she realized that their lifestyles are too different. She spoke openly about not wanting to make friends with the domestic students on her floor, stating that they are "really crazy" and like to "play loud music." Vicky credited her discomfort with her floormates to cultural differences and the lack of conversation topics between Chinese and American students. She mostly socialized with her roommate and other Chinese friends since she did not feel a connection with others on her floor.

Most participants in this study decided to live with another Chinese student for their second academic year. Several participants cited the need to be comfortable in their living space as their reason. Of the 21 participants, only six chose to live in on-campus housing for their second year. The other 15 participants decided to move off campus and all of them chose to live with other Chinese students. Their choices in housing for their second academic year indicated that for many of the participants, the residence halls do not necessarily provide a very comfortable living space.

\section{DISCUSSION}

Most of the participants with American roommates in this study indicated a relatively low sense of belonging in their residence halls. Many participants faced interpersonal challenges with American students in the residence halls as a result of their national origin. This finding is not surprising since relevant literature indicates that feelings of belonging in residence hall communities tended to be higher for White students than for students of color (Berger, 1997; Johnson et al., 2007), likely due to "a dominant peer normative environment” (Berger, 1997, p. 449) based on White student culture that likely affects underrepresented students. The existence of a dominant normative environment is not easy to navigate, particularly for international students who are temporary visitors to a different cultural environment.

Although some participants had positive experiences with American students, they tended to be outliers in this study. Most of the participants in this study lack a sense of belonging in their residence halls. Participants with Chinese roommates indicated a sense of belonging inside their rooms, but not so much in the overall residential community. Most participants with domestic roommates were unhappy with their roommate relationships, which affected their feelings of belonging in their rooms. The minimal feelings of belonging could be a result of feeling like they are outsiders and not full members of the residential community.

Several students indicated they were fairly comfortable in their rooms, but they did not necessarily feel like they were a part of the community in their residence halls. These findings were not surprising when 
considering the importance of interpersonal relationships on overall residential satisfaction (Blimling, 2010; Pascarella \& Terenzini, 2005; Pascarella, Terenzini, \& Blimling, 1994; Pike, 2002). Findings from this study indicate a need to reexamine assumptions that intercultural engagement would happen naturally in close living quarters. As indicated by the participants' expectations of interactions with American students and prior studies (Pan \& Wong, 2011; Sherry et al., 2010; Yan \& Berliner, 2011), the challenges of cultural and language barriers between newly arrived Chinese and domestic students are too significant to leave to chance. Consideration of environmental factors (Glass, 2012) such as interactive programs and facilitated dialogue could lead to higher sense of belonging for Chinese students in residence halls.

Although the Chinese participants with American roommates have a relatively low sense of belonging to residence hall communities, there is a compelling case for international students living on campus in residence halls. This is particularly true for those who are in the first year of their collegiate career. Living on campus has a positive influence on first-year students' sense of belonging (Johnson et al, 2007). The residence hall can be a "compelling environment for shaping students' sense of belonging" (Johnson et al., 2007, p. 536), which is similar to previous studies on firstyear students that found positive effects of residence halls on students' socialization and sense of community (Berger, 1997). The value of oncampus living was illustrated by the participants' housing situations in their second year at the university. Of the 21 participants, only six Chinese students chose to remain living on-campus for their second year. However, most of the off-campus students stated in their second interviews that they wished they had stayed on campus for two reasons: convenience and increased interaction with American students. These participants indicated that living in residence halls helped with their overall feelings of connectedness to the larger campus community.

Some areas of further research are needed for better understanding Chinese students' residential experiences. A longitudinal study that examines how Chinese students' sense of belonging changes over the course of their collegiate career is needed since increased duration on campus could lead to increased sense of belonging.

\section{RECOMMENDATIONS FOR PRACTICE}

Participants with low sense of belonging spoke extensively about cultural differences and language challenges that they experienced with domestic roommates. Both formal and informal measures could improve the sense of belonging in Chinese international students. Formal structures should be put in place related to programmatic requirements of university staff, and 
programs are particularly important since this indicates an investment in a departmental and/or institutional priority of intercultural interactions. Early planning and campus-wide collaboration should be at the forefront of developing effective and successful programs. For example, residence life and student services could sponsor domestic and Chinese roommate pairings to attend local/campus events so they have a discussion topic on a shared common experience.

Another example of a collaborative, campus-wide program would be to develop an early orientation to living on campus for both international and domestic students. Orientation programs tend to fall under the purview of universities' new student orientation office or international student advising center; however, all departments should play a significant role in welcoming and preparing students to live on campus. By facilitating early preparation for all students, both domestic students and international students will be better equipped to live with roommates in community spaces. In doing so, some of the responsibility for creating positive living environments shifts into the purview of domestic students. Rather than only expecting Chinese students to adapt to a new collegiate environment, domestic students should also prepare to live in a diverse residential environment with students from a variety of nationalities and backgrounds.

Informal measures for intercultural exchange are likely more influential on Chinese student and domestic student interactions since they occur more frequently than planned programs. Informal programs and events still require planning and outcomes; however, the nature of the programs would be less structured in order to allow more fluidity in participation. The challenge will be to brainstorm informal programs that will engage all residential students, and much of the success will be based on the contextual factors such as residence hall theme, institutional priorities, and architectural space. An example of informal programs for residence life staff could include monthly bulletin boards that are related to current popular topics, including world news, emerging music artists, or current campus issues. These informational posts could serve as conversation topics for students on the residence hall floor. The participants in this study had all studied English as a second language prior to arriving to the United States. However, English language classes typically follow formal sentence and grammar structures that limit the use of informal conversational English that permeates communication among college-aged students. Thus, creative use of bulletin boards could be an opportunity for international students to learn more about colloquial terms and pop culture references from other students in their residence halls.

In addition to programmatic interventions, student affairs professionals and student staff must be prepared to assist in facilitating cross-cultural interactions. As indicated by participants' experiences, many 
Chinese students had positive interactions with their roommates early in their first semester. Continuous and meaningful peer interaction requires well-trained resident assistants and other student leaders who are committed to creating and fostering intercultural interactions with all of their residents. Training on proactively assessing roommate relationships is imperative for all residence hall staff members, particularly resident assistants who are living in close proximity to international students. Resident assistants are influential through their daily interactions and program planning for residents; thus, it is imperative that student staff are trained to facilitate intercultural dialogue and interactions among all residents early in the academic year.

Student affairs professionals must be comfortable with and understand their roles as facilitators and resources in order to best support conversations and interaction among diverse students (Quaye, 2012). Training processes could take advantage of the knowledge base that already exists on campus, such as international student support offices, through collaborative facilitation and programs. University staff should invest in intentional training on fostering intercultural interactions for domestic and international students. Training for student affairs professionals is imperative to ensuring success for all student members of the university community.

\section{CONCLUSION}

The majority of participants requested an American roommate for their first year, with the expectation that domestic roommates would help international students bridge the gap to American culture. However, many participants came to feel uncomfortable in their residence hall, citing a lack of connection with American students. The participants' feelings of discomfort in their residence hall led to decreased interactions with American students and some tension with roommate relationships. Overall, findings indicate a less than satisfactory residential experience for the Chinese participants in this study, all of which negatively affected the participants' sense of belonging in the residence halls.

\section{REFERENCES}

Astin, A.W. (1993). What matters in college? Four critical years revisited. San Francisco, CA: Jossey-Bass.

Berger, J.B. (1997). Students' sense of community in residence halls, social integration, and first-year persistence. Journal of College Student Development, 38(5), 441-452. 
Blimling, G. (2010). The resident assistant: Applications and strategies for working with college students in residence halls. Dubuque, IA: Kendall Hunt Publishing.

Creswell, J.W. (2007). Qualitative inquiry and research design: Choosing among five approaches (2nd ed.). Thousand Oaks, CA: Sage.

Freeman, T.M., Anderman, L.H., \& Jensen, J.M. (2007). Sense of belonging in college freshmen at the classroom and campus levels. The Journal of Experimental Education, 75(3), 203-220.

Glass, C.R. (2012). Educational experiences associated with international students' learning, development, and positive perceptions of campus climate. Journal of Studies in International Education, 16(3), 228-251.

Glesne, C. (2006). Becoming qualitative researchers: An introduction (4trd ed.). Boston, MA:

Pearson.Hausmann, L.R., Ye, F., Schofield, J.W., \& Woods, R.L. (2009). Sense of belonging and persistence in White and African-American first-year students. Research in Higher Education, 50, 649-669.

Hurtado, S., \& Carter, D.F. (1997). Effects of college transition and perceptions of the campus racial climate on Latino college students' sense of belonging. Sociology of Education, 70(4), 324-345.

Institute of International Education (2013). Open doors 2013: International student in the United States and study abroad by American students are at all-time high. Retrieved from http://www.iie.org/Who-We-Are/News-andEvents/Press-Center/Press-Releases/2013/2013-11-11-Open-Doors-Data

Johnson, D.R., Soldner, M., Leonard, J.B., Alvarez, P., Inkelas, K.K., RowanKenyon, H., \& Longerbeam, S. (2007). Examining sense of belonging among first-year undergraduates from different racial/ethnic groups. Journal of College Student Development, 48(5), 525-542.

Lee, J.J. (2010). International students' experiences and attitudes at a US host institution: Self-reports and future recommendations. Journal of Research in International Education, 9(1), 66-84.

Lee, J. J., \& Rice, C. (2007). Welcome to America? International student perceptions of discrimination. Higher Education, 53, 381-409.

Li, R.Y., \& Kaye, M. (1998). Understanding overseas students' concerns and problems. Journal of Higher Education Policy and Management, 20(1), 41-50.

Merriam, S.B. (2009). Qualitative research: A guide to design and implementation. San Francisco, CA: Jossey-Bass.

Miles, M. B., Huberman, A. M., \& Saldaña, J. (2013). Qualitative data analysis: A methods sourcebook ( $3^{\text {rd }}$ Edition). Thousand Oaks, CA: Sage.

Museus, S. D., \& Maramba, D. C. The impact of culture on Filipino American students' sense of belonging. The Review of Higher Education, 34(2), 231258.

Pan, J.Y., \& Wong, D.F.K. (2011). Acculturative stressors and acculturative strategies as predictors of negative affect among Chinese international students in Australia and Hong Kong: A cross-cultural comparative study. Academic Psychiatry, 35(6), 376-381.

Pascarella, E.T., \& Terenzini, P.T. (2005). How college affects students. San Francisco, CA: Jossey-Bass. 
Pascarella, E. T., Terenzini, P. T., \& Blimling, G. S. (1994). The impact of residential life on students. In C. Schroeder \& P. Mable (Eds.), Realizing the educational potential of residence halls (pp. 22-52). San Francisco, CA: Wiley.

Patton, M. (12002). Qualitative research and evaluation methods ( $3^{\text {rd }}$ ed.). Thousand Oaks, CA: Sage.

Pike, G. R. (2002). The differential effects of on- and off-campus living arrangements on students' openness to diversity. NASPA Journal, 39, 284299.

Quaye, S.J. (2012). Think before you teach: Preparing for dialogues about racial realities. Journal of College Student Development, 53, 542-562.

Rossman, G.B., \& Rallis, S.F. (2003). Learning in the field: An introduction to qualitative research. Thousand Oaks, CA: Sage.

Sherry, M., Thomas, P., \& Chui, W.H. (2010). International students: A vulnerable student population. Higher Education, 60, 33-46.

Shushok, F., Scales, T. L., Sriram, R., \& Kidd, V. (2011). A tale of three campuses: Unearthing theories of residential life that shape the student learning experience. About Campus, 16(3), 13-21.

Smith, R.A., \& Khawaja, N.G. (2011). A review of the acculturation experiences of international students. International Journal of Intercultural Relations, 35, 699-713.

Strayhorn, T. L. (2012). College students' sense of belonging: A key to educational success for all students. New York, NY: Routledge.

Tinto, V. (1993). Leaving college: Rethinking the causes and cures of student attrition. Chicago, IL: The University of Chicago Press.

UNESCO Institute for Statistics. (2014). Global flow of tertiary-level students. Retrieved from http://www.uis.unesco.org/Education/Pages/internationalstudent-flow-viz.aspx

Van Manen, M. (1990). Researching lived experience: Human science for an action sensitive pedagogy. Albany, NY: State University of New York Press.

Wilton, L., \& Constantine, M.G. (2003). Length of residence, cultural adjustment difficulties, and psychological distress symptoms in Asian and Latin American international students. Journal of College Counseling, 6, 177186.

Yan, K., \& Berliner, D.C. (2011). Chinese international students in the United States: demographic trends, motivations, acculturation features and adjustment challenges. Asia Pacific Education Review, 12, 173-184.

CHRISTINA W. YAO, PhD, is an Assistant Professor of Educational Administration at the University of Nebraska-Lincoln. Her research addresses graduate and undergraduate student experiences in higher education, international and comparative education, and critical qualitative methods. Email: cyao@unl.edu

Manuscript submitted: June 16, 2015

Manuscript revised: October 9, 2015 Accepted for publication: November 8, 2015 